EMBRYARIDDLE
Aeronautical University

SCHOLARLY COMMONS

\section{International Journal of Aviation,} Aeronautics, and Aerospace

7-4-2016

\title{
Quantifying the Effects of Humidity on Density Altitude Calculations for Professional Aviation Education
}

Thomas A. Guinn

Embry-Riddle Aeronautical University - Daytona Beach, Thomas.Guinn@erau.edu

Randell J. Barry

Embry-Riddle Aeronautical University - Daytona Beach, barryc69@erau.edu

Follow this and additional works at: https://commons.erau.edu/ijaaa

Part of the Aviation Safety and Security Commons, and the Meteorology Commons

\section{Scholarly Commons Citation}

Guinn, T. A., \& Barry, R. J. (2016). Quantifying the Effects of Humidity on Density Altitude Calculations for Professional Aviation Education. International Journal of Aviation, Aeronautics, and Aerospace, 3(3). https://doi.org/10.15394/ijaaa.2016.1124

This Article is brought to you for free and open access by the Journals at Scholarly Commons. It has been accepted for inclusion in International Journal of Aviation, Aeronautics, and Aerospace by an authorized administrator of Scholarly Commons. For more information, please contact commons@erau.edu. 


\section{Quantifying the Effects of Humidity on Density Altitude Calculations for Professional Aviation Education}

\section{Cover Page Footnote}

We would like to thank the two reviewers for the thoughtful comments. 
Density altitude is defined as the altitude at which a given density occurs in the standard atmosphere. Since many basic flight characteristics, such as lift and thrust, depend directly on air density, the density altitude helps provide a relative measure of aircraft performance, with higher density altitudes corresponding to decreased performance. Because of the importance of density altitude to flight safety, the calculation of density altitude is an integral part of flight planning and therefore a critical component of professional flight education. Despite the importance of accurate density altitude calculations, most introductory pilot training manuals fail to address the impact atmospheric humidity has on the results. For example, FAA (1975), Lester (2007), FAA (2014), USAF (1997), and FAA (2016) do not even mention humidity has an impact on density altitude calculations. In comparison, FAA (2008) does provide a descriptive overview relating the negative impact of humidity on density altitude, but it only provides a single example to demonstrate the potential magnitude of the error. The manual concludes by mentioning no simple rules of thumb (ROTs) exist for humidity and refers the reader to two websites providing online calculators. Given the limited available educational information on the topic, aviation students are not likely familiar with the magnitude of the impact humidity on their flight planning.

The purpose of this paper is to provide a comprehensive quantification of the effects of humidity on density altitude calculations and graphically display the results over a wide range of possible temperatures, pressure levels, and humidity values. Also, we have created a representative 10-year climatology of dew-point temperature values for various locations across the U.S. to give the reader an awareness of expected and worst-case humidity conditions. The graphical displays used together with the climatology should allow both students and aviation educators to demonstrate better the conditions where humidity makes a significant difference on density altitude calculations and where it has limited impact.

We begin the paper with a brief overview and discussion of the concept of humidity, to include different forms in which it is quantified and their relationship to density altitude calculations. Next, we examine and discuss the effects of dewpoint temperature on density altitude calculations for a variety of temperatures and pressure altitudes as well as provide a brief climatology overview of dew-point temperatures at various representative U.S. locations. We then present and discuss a simple ROT that incorporates the effects of humidity on density altitude calculations to include the error characteristics of the ROT. The paper concludes 
with a discussion of potential uses and limitations of the information in professional aviation education.

\section{Literature Review}

\section{Review of Humidity Measurements}

Humidity is a general term referring to some measure of the water vapor content of the air (AMS, 2000). In meteorology, there exists a variety of means to quantify humidity depending on the application in which it is to be used. For most general aviation-related applications, the three most common measurements are typically dewpoint temperature, relative humidity, and temperature/dew-point temperature spread. However, for the calculation of density altitude, the vapor pressure (and the related saturation vapor pressure) becomes a useful measure of humidity. These variables are compared below.

The dew-point temperature is the temperature to which air must be cooled at constant pressure for saturation to occur. It provides an effective measure of the actual amount of water vapor in the atmosphere. The greater the dew-point temperature, the greater the amount of water vapor in the air. The dew-point temperature can only be increased (at constant pressure) by increasing the amount of water vapor in the air.

Dew-point temperature, however, doesn't provide any measure of how close the air is to saturation. For this, we use the relative humidity. The relative humidity provides the ratio of the amount of water vapor in the air compared to the amount required for saturation (at the same pressure). This is particularly useful for predicting when condensation will begin, such as in fog forecasting. Unlike dew-point temperature, however, the relative humidity provides no measure of the actual amount atmospheric water vapor in the air. For example, warm air can have a low relative humidity despite having a higher dew-point temperature, and therefore higher water-vapor content than nearly saturated air at cold temperatures.

Related to relative humidity is the temperature dew-point spread (i.e. the difference between the temperature and dewpoint temperature). Like relative humidity, the temperature dew-point spread also provides a measure of how close the air is to saturation, but again it is not a direct measure of the actual amount of water vapor in the air. 
For density altitude calculations, the vapor pressure is a more useful measure of water-vapor content, as we'll see in the next section. The vapor pressure is simply the contribution to the total atmospheric pressure made by the water vapor alone, and like atmospheric pressure, it has units of millibars $(\mathrm{mb})$ or Pascals $(\mathrm{Pa})$. The more water vapor in the atmosphere, the greater will be the vapor pressure. When the vapor pressure increases to the point at which condensation occurs, we say the air is saturated, and the vapor pressure at which this first occurs is referred to as the saturation vapor pressure. Unlike vapor pressure, the saturation vapor pressure is a monotonic function solely of temperature. As the temperature increases, the saturation vapor pressure also increases. The ratio of the two (vapor pressure over saturation vapor pressure) multiplied by 100 to express as a percentage also provides a definition of the relative humidity discussed earlier (AMS, 2000).

To get a sense for the magnitude of typical vapor pressures, we first note the saturation vapor pressure at $25^{\circ} \mathrm{C}$ is approximately $16 \mathrm{mb}$, while the saturation vapor pressure at $0^{\circ} \mathrm{C}$ is approximately $6 \mathrm{mb}$. This, therefore, gives us an upper limit of the actual vapor pressure observed at these temperatures. Comparing these values with the standard atmospheric pressure of $1013 \mathrm{mb}$, we see the vapor pressure typically only accounts for less than $2 \%$ of the total atmospheric pressure. While small, this amount of water vapor can still have a non-negligible effect on air density and therefore aircraft performance.

\section{General Impacts of Humidity on Density Altitude}

The calculation of density altitude using simple charts or manual flight computers (e.g., E6-B) only requires knowledge of the pressure altitude and the air temperature. However, astute aviation students will quickly notice electronic flight calculators require the dew-point temperature as an additional input. This is because electronic flight calculators use more sophisticated algorithms that account for the effect of water vapor on air density, and the dew-point temperature provides a direct measure of the amount of water vapor in the air.

To understand the effect of water vapor on air density more clearly, consider that dry air has a mean molecular weight of $28.9944 \mathrm{~g} / \mathrm{mol}$ (NOAA, 1976), while water vapor has a molecular weight of only $18.05128 \mathrm{~g} / \mathrm{mol}$. Because of the lower molecular weight, adding water vapor to dry air lowers the average molecular 
weight of the air in a given volume. Thus an increase in the amount of water vapor in the air leads to a decrease in air density, which in turn leads to an increase in the density altitude. That is, with increased humidity, an aircraft will perform as if it's higher in the standard atmosphere than it would at the same temperature but with a dry atmosphere (at the same pressure). To calculate the density altitude accurately, we must, therefore, incorporate the air's moisture content into the calculation.

\section{Calculation of Density Altitude}

The equation for density altitude $\left(h_{d}\right)$ for the dry atmosphere $(1)$ is derived in detail in Appendix A. The equation provides the altitude at which a given density occurs in the standard atmosphere.

$$
h_{d}=\frac{T_{o}}{L}\left[\left(\frac{\rho}{\rho_{o}}\right)^{-\left(\frac{R_{d} L}{g_{o+R} L}\right)}-1\right] \text {, }
$$

where $h_{d}$ is the geopotential altitude, $T_{o}$ is the standard mean sea-level temperature of $288.15 \mathrm{~K}, \rho$ is density, $\rho_{o}$ is the standard mean sea-level atmospheric density, $g_{o}$ is gravity $\left(9.80665 \mathrm{~ms}^{-2}\right.$, NOAA, 1976), $R_{d}$ is the gas constant for dry air (287.053 $\mathrm{Jkg}^{-1} \mathrm{~K}^{-1}$ ), and $L$ is the standard tropospheric lapse rate of $-6.5 \mathrm{~K} / \mathrm{km}$ (NOAA, 1976). However, because density is a difficult quantity to observe and measure, we typically find it more convenient to use the ideal gas law (A6) to express density in terms of more readily observed variables, namely pressure and temperature. Thus (1) can be rewritten in a more useful form as

$$
h_{d}=\frac{T_{o}}{L}\left[\left(\frac{p}{p_{o}} \cdot \frac{T_{o}}{T}\right)^{-\left(\frac{R_{d} L}{g_{o+R} L}\right)}-1\right] .
$$

Equation (2) represents the desired density-altitude equation as a function of pressure and temperature for dry air. It provides the geopotential altitude at which a given pressure and temperature (therefore density) occurs in the standard atmosphere. While the expression for pressure altitude (A5) is a function only of pressure, we notice our expression for density altitude (2) is a function of both pressure and temperature. Thus, density altitude is frequently described as the pressure altitude "corrected" for non-standard temperature (e.g., FAA, 2014; 
Lester, 2007). Figure 1 shows the variation in density altitude with temperature over the temperature range $50-100^{\circ} \mathrm{F}$ for pressure values corresponding to pressure altitudes of 0,3,000, 6,000 and 9,000 feet. This figure will be used as a basis for comparison with cases where atmospheric moisture is considered.

Figure 1 demonstrates two interesting results. The first is that despite density altitude being an exponential function of temperature when we evaluate over the relatively small observed range of tropospheric temperatures, the equation behaves nearly linearly. This leads to the well-known ROT that density altitude increases approximately 120 feet (70 feet) for every $1{ }^{\circ} \mathrm{C}\left(1^{\circ} \mathrm{F}\right)$ increase in temperature above the standard atmospheric temperature. To see this linear relationship more clearly, we compute the derivative of (2) with respect to temperature while holding pressure constant, which shown in (3).

$$
\left(\frac{\partial h_{d}}{\partial T}\right)_{p}=\frac{T_{o}}{T}\left(\frac{R_{d}}{g_{o}+R_{d} L}\right)\left(\frac{p}{p_{o}} \cdot \frac{T_{o}}{T}\right)^{-\left(\frac{R_{d} L}{g_{o+R_{d}} L}\right)}
$$

While (3) appears complicated, if we evaluate the expression at standard mean sealevel temperature and pressure, (3) reduces to the constant:

$$
\left(\frac{\partial h_{d}}{\partial T}\right)_{p=p_{o}}=\left(\frac{R_{d}}{g_{o}+R_{d} L}\right)=118.5 \text { feet } /{ }^{\circ} \mathrm{C}
$$

Since the remaining terms in expression in (3) are nearly equal to one for typical surface elevations and climatological temperatures, the relationship of $120 \mathrm{feet} /{ }^{\circ} \mathrm{C}$ (70 feet $/{ }^{\circ} \mathrm{F}$ ) remains relatively constant. We can clearly see this linear relationship as we move horizontally in the direction of increasing temperature along any of the curves in Fig. 1. In doing so, we notice for every $10^{\circ} \mathrm{F}$ the density altitude increases approximately 700 feet.

The second, equally interesting, the result can be seen in the case where we move vertically along a constant temperature line. Here we notice the density altitude increases by approximately 3,800 feet for every 3,000 foot change in 


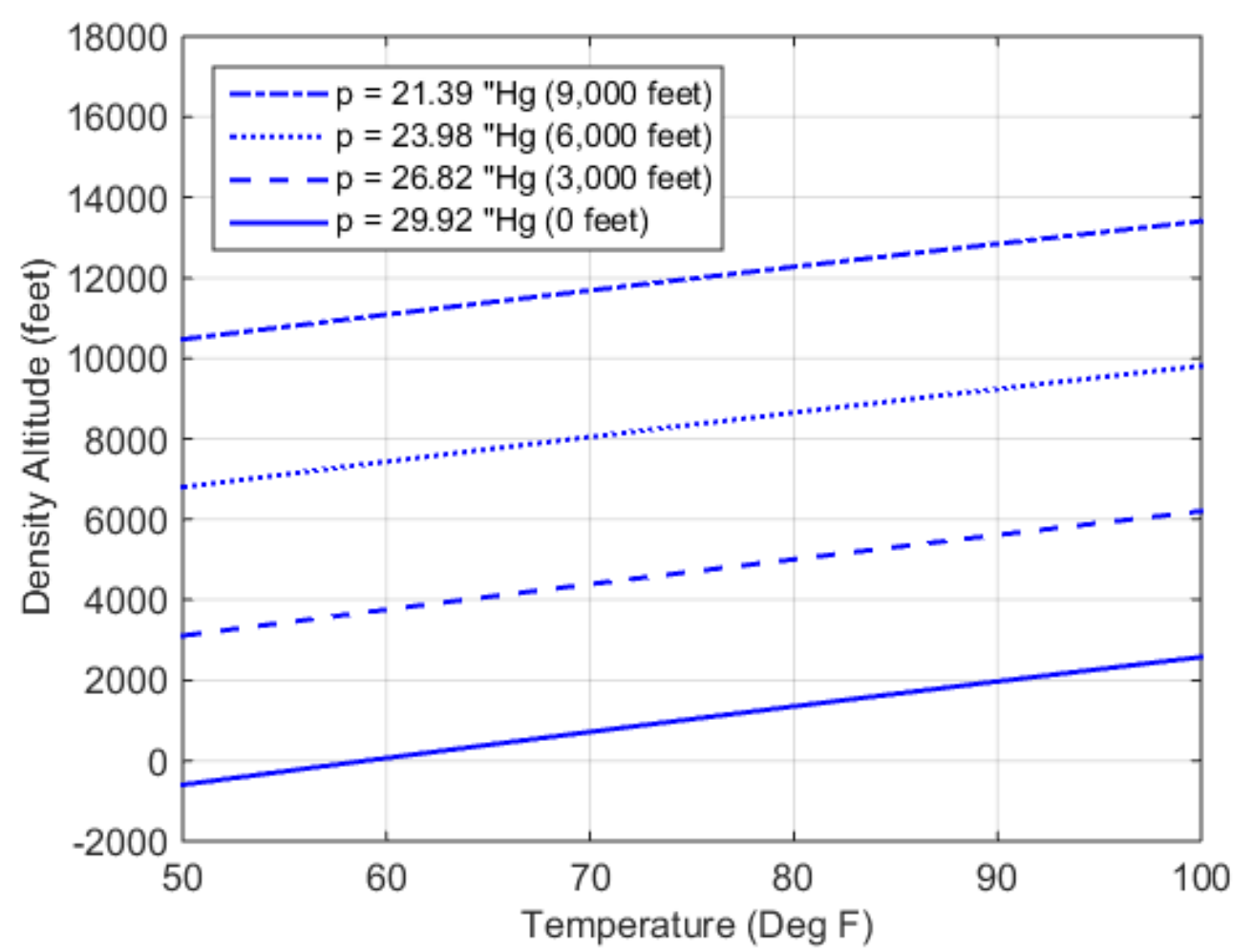

Figure 1. Change in density altitude with temperature for dry air at pressure altitudes at 0, 3000, 6000, 9000 feet.

pressure altitude. This can also be explained by the classic ROT of 120 feet increase in density altitude for every $1^{\circ} \mathrm{C}$ above standard temperature. To see this, recall the standard tropospheric temperature lapse rate is $-6.5^{\circ} \mathrm{C} / \mathrm{km}$ (or $-2.0^{\circ} \mathrm{C} / \mathrm{kft}$ ). So when moving vertically along a constant temperature line, the standard atmospheric temperature will decrease by nearly $6^{\circ} \mathrm{C}$ as we move from the surface to a pressure altitude of 3,000 feet, even though the temperature of the line remains constant. At 3,000 feet the constant temperature, we are following on the graph will now be $6^{\circ} \mathrm{C}$ warmer than the standard atmospheric temperature. When we apply the ROT, this temperature difference equates to an additional density altitude increase of approximately 780 feet. The result is a net change of approximately 3,800 feet when ascending from mean sea level to a pressure altitude of 3,000 feet at a constant temperature. 


\section{Incorporating Humidity into Density-Altitude Calculations}

To incorporate the effect of humidity on density altitude, we first need to quantify the change in density resulting from the addition of water vapor to the air. In meteorology this is most typically accomplished by calculating a virtual temperature; that is, the temperature dry air would require to have the same density as humid air at the same pressure. By using virtual temperature, we can retain the gas constant for dry air rather than determining a new gas constant whenever the mean molecular weight of the air changes due to the addition or subtraction of water vapor.

The virtual temperature, $T_{v}$, can be calculated using the following equation, the derivation of which is found in a variety of meteorology text books (e.g., Wallace and Hobbs, 2006). The equation is

$$
T_{v}=\frac{T}{1-(e / p)(1-\varepsilon)}
$$

where $e$ is the vapor pressure and $\varepsilon$ is the ratio of the molecular weight of water vapor to the molecular weight of dry air $(\varepsilon=0.622)$. Since the denominator in (5) is always less than one when water vapor is present, $T_{v}$ will always be slightly greater than the actual temperature. Physically this may be interpreted using the ideal gas law (A6) and noticing that since moist air is less dense than dry air i.e. smaller $\rho$, dry air would require a slightly higher temperature to have the same density as humid air, again assuming constant pressure.

As seen in (5) calculating the virtual temperature requires a method to calculate the vapor pressure, or more specifically, the saturation vapor pressure. Numerous algorithms for calculating saturation vapor pressure as a function of temperature are available, ranging from relatively simple, such as Bolton (1980) and Lowe (1974), to more complex eighth-order, curve-fitted, polynomial functions designed for computational efficiency (Flatau et al., 1992). Here we choose to use Hyland and Wexler (1983), which provides relatively high accuracy albeit with increased computational expense. However, given the small number of calculations for our experiments, computational efficiency is only a minor concern 
compared to accuracy. Hyland and Wexler's (1983) formulation is described in detail in Appendix B.

Hyland and Wexler's equations (B1) and (B2) provide the saturation vapor pressure over water (B1) and ice (B2) in units of Pascals for a given input temperature (in Kelvins). However, the calculation of virtual temperature requires the actual vapor pressure. The actual vapor pressure can be obtained simply by inputting the dew-point temperature into Hyland and Wexler's equations. Thus the calculation of the virtual temperature requires knowledge of the temperature, dewpoint temperature, and pressure.

Before incorporating virtual temperature into the calculation of density altitude, it's beneficial to examine the change in virtual temperature with dew-point temperature. To examine this effect, Fig. 2 shows the variation in virtual temperature with dew-point temperature for $90^{\circ} \mathrm{F}$ air for four different pressures corresponding to pressure altitudes of $0,3,000,6,000$, and 9,000 feet. The difference between temperature and virtual temperature can be significant to density altitude calculations, as we'll see in the next section. Also of interest to note is that the slope of the lines is not linear; that is, a change in dewpoint temperature by one degree has a greater impact on the virtual temperature when the dew-point temperatures are large than when they are small. Another key point is that for a fixed dew-point temperature (i.e. fixed vapor pressure), the virtual temperature increases as the pressure altitude changes. For example, given a dewpoint temperature of $80^{\circ} \mathrm{F}$, the difference between the temperature and virtual temperature at 9,000 feet is approximately $3^{\circ} \mathrm{F}$ greater than it is at standard mean sea-level pressure. This suggests airports located at higher elevations will experience slightly greater changes in density altitude as the dew-point temperature increases than will airports located at lower elevations. However, as we'll see later, this effect is small over normal ranges of dew-point temperatures, and only minimally significant for very high dewpoint temperatures at high elevations.

We can now use virtual temperature to adjust density altitude for humidity. We do this by replacing $T$ with $T_{v}$ in (2), which gives our desired relationship for density altitude with the effect of humidity included. 


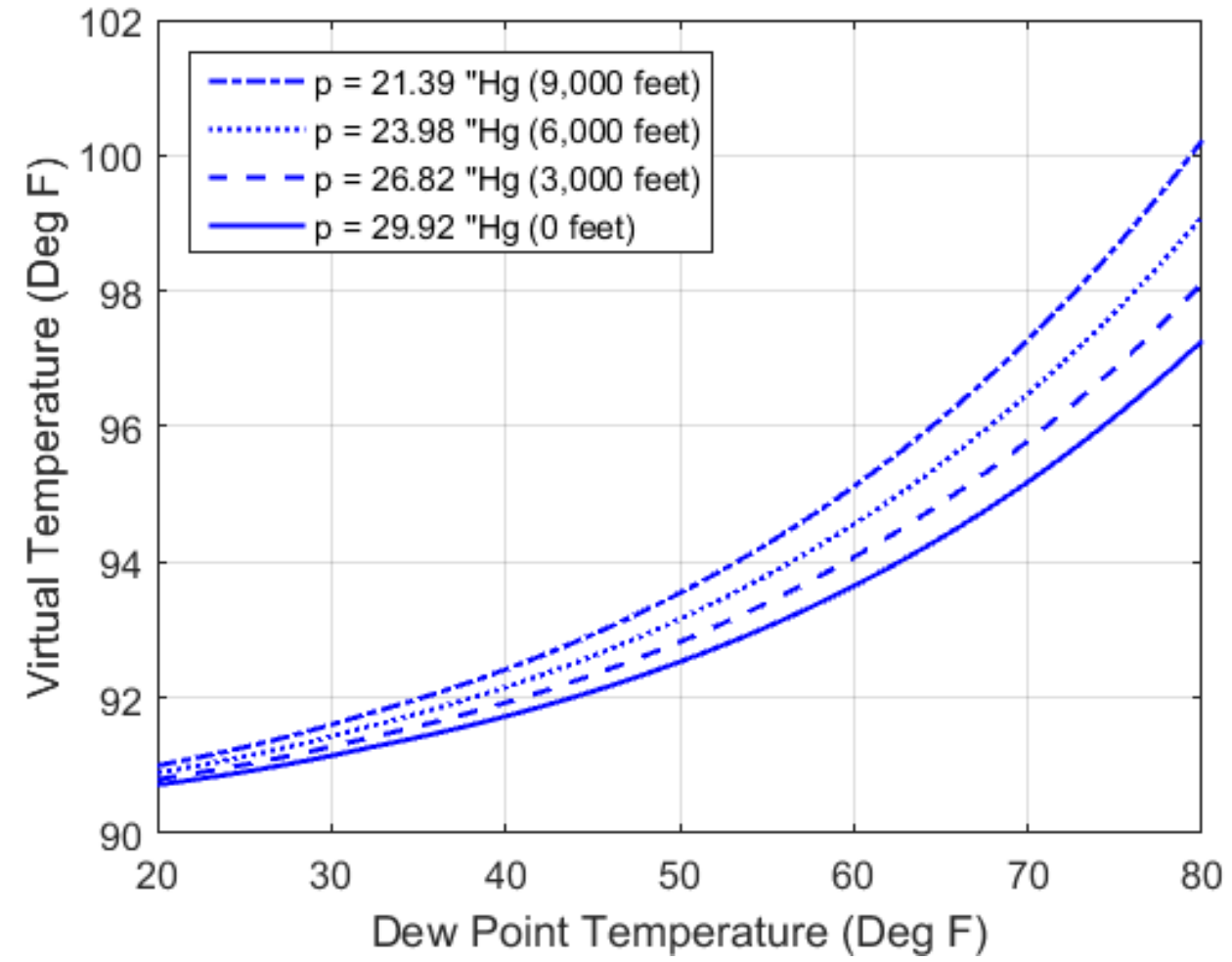

Figure 2. Change in virtual temperature with dew point temperature for $90^{\circ} \mathrm{F}$ air at pressure altitudes of $0,3,000,6,000$, and 9,000 feet.

$$
h_{m}=\frac{T_{o}}{L}\left[\left(\frac{p}{p_{o}} \cdot \frac{T_{o}}{T_{v}}\right)^{-\left(\frac{R_{d} L}{g_{o+R} L}\right)}-1\right]
$$

Equation (6) now provides the geopotential height of a given density in the standard atmosphere, where density is a function of temperature, pressure, and humidity. Here the subscript " $m$ " is used to indicate a "moist" atmosphere is now considered, i.e. one that includes water vapor. Thus, the density altitude for a moist atmosphere can be calculated from three variables: temperature, pressure and dew-point temperature. Lastly, we note the conversion from geopotential to geometric altitude is provided in Appendix A, although the correction is negligible $(<0.05 \%)$ for elevations below 10,000 feet. 


\section{Method}

To show the effect of humidity on density altitude, we used MATLAB $\AA$ to evaluate and graphically display results from the equation for density altitude (6) over a wide range of climatologically appropriate temperature, dew-point temperature, and relative humidity values at various pressure altitudes using four different methods. With the first method, we used (6) to plot nomograms showing the density altitude as a function of temperature and dew-point temperature for both standard mean sea-level pressure as well as a pressure altitude of 6,000 feet. Second, we used (6) combined with the definition of relative humidity to calculate density altitude as a function of relative humidity for a specified temperature. Third, we again used (6) both with and without the virtual temperature correction to compare the effects of disregarding humidity on density altitude calculations. We again created nomograms to display both the absolute error and percent error as a function of temperature and dew-point temperature for both standard mean sealevel pressure and a pressure altitude of 6,000 feet. Lastly, we used these differences to construct a simple ROT using basic linear regression techniques.

For creating the dew-point temperature climatology table, we used hourly observation data available from the National Centers for Environmental Information (NCEI, 2016). We used a ten-year period of record from June 2006 to August 2015 to construct monthly averages, maximum, and minimum dew-point temperature values for the months of June, July, and August. These months were chosen to capture the highest dewpoint temperature values for most locations. The locations, themselves, were chosen based on two criteria. First, they were chosen to represent a sample of nearly all climatic regimes in the contiguous U.S. to yield the greatest variability. Second, they were chosen for their proximity to professional flight programs in hopes of increasing classroom use. The results of the climatology are provided in Table 1.

\section{Results}

\section{Graphical Depictions Quantifying the Impact of Humidity on Density Altitude}

In Fig. 3 we show density altitude as function of temperature and dew-point temperature at (a) standard sea-level pressure and (b) a pressure altitude of 6,000 
Table 1.

Ten-year period of record (2006-2015) Dew-Point Temperature Climatology for the months June, July, and August at various locations across the contiguous U.S.

\begin{tabular}{|c|c|c|c|c|c|c|c|c|c|c|}
\hline \multirow[b]{2}{*}{ Location (ICAO) } & \multirow[b]{2}{*}{$\begin{array}{l}\text { Elev. } \\
\text { (feet) }\end{array}$} & \multicolumn{3}{|c|}{ June } & \multicolumn{3}{|c|}{ July } & \multicolumn{3}{|c|}{ August } \\
\hline & & $\begin{array}{c}\text { Max. } \\
\left({ }^{\circ} \mathbf{F}\right)\end{array}$ & $\begin{array}{l}\text { Avg. } \\
\left({ }^{\circ} \mathbf{F}\right)\end{array}$ & $\begin{array}{l}\text { Min. } \\
\left({ }^{\circ} \mathbf{F}\right)\end{array}$ & $\begin{array}{c}\text { Max. } \\
\left({ }^{\circ} \mathbf{F}\right)\end{array}$ & $\begin{array}{l}\text { Avg. } \\
\left({ }^{\circ} \mathbf{F}\right)\end{array}$ & $\begin{array}{l}\text { Min. } \\
\left({ }^{\circ} \mathbf{F}\right)\end{array}$ & $\begin{array}{c}\text { Max. } \\
\left({ }^{\circ} \mathbf{F}\right)\end{array}$ & $\begin{array}{l}\text { Avg. } \\
\left({ }^{\circ} \mathbf{F}\right)\end{array}$ & $\begin{array}{l}\text { Min. } \\
\left({ }^{\circ} \mathbf{F}\right)\end{array}$ \\
\hline $\begin{array}{l}\text { Daytona Beach, FL } \\
\text { (KDAB) }\end{array}$ & 34 & 79.0 & 70.5 & 41.0 & 81.0 & 72.7 & 60.1 & 80.1 & 73.5 & 61.0 \\
\hline Denver, CO (KDEN) & 5434 & 64.9 & 42.6 & 3.9 & 64.9 & 48.9 & 17.1 & 66.0 & 47.2 & 16.0 \\
\hline Ellensburg, WA (KELN) & 1764 & 66.0 & 43.2 & 16.0 & 66.0 & 46.8 & 15.1 & 64.9 & 46.8 & 17.1 \\
\hline Grand Forks, ND (KGFK) & 845 & 77.0 & 53.5 & 28.0 & 79.0 & 59.0 & 37.9 & 75.9 & 56.8 & 37.0 \\
\hline Kalamazoo, MI (KAZO) & 874 & 75.0 & 57.0 & 33.1 & 79.0 & 60.4 & 36.0 & 77.0 & 60.0 & 39.9 \\
\hline Lynchburg, VA (KLYH) & 938 & 75.9 & 62.3 & 41.0 & 78.1 & 65.0 & 39.9 & 79.0 & 64.5 & 37.9 \\
\hline $\begin{array}{l}\text { (KMGnigomery, AL } \\
\text { (KMG) }\end{array}$ & 221 & 78.1 & 67.6 & 45.0 & 79.0 & 70.2 & 46.9 & 80.1 & 70.1 & 48.0 \\
\hline Nashville, TN (KBNA) & 599 & 78.1 & 63.9 & 39.0 & 80.1 & 66.7 & 46.9 & 78.1 & 65.6 & 43.0 \\
\hline Omaha, NE (KOMA) & 984 & 81.0 & 60.7 & 32.0 & 80.1 & 65.0 & 42.1 & 81.0 & 64.3 & 33.1 \\
\hline Prescott, AZ (KPRC) & 5045 & 66.0 & 27.9 & -11.0 & 66.9 & 49.4 & -2.9 & 66.9 & 49.8 & 10.0 \\
\hline Stillwater, OK (KSWO) & 1000 & 77.0 & 65.4 & 43.0 & 80.1 & 66.2 & 46.9 & 78.8 & 65.2 & 35.1 \\
\hline Taunton, MA (KTAN) & 42 & 75.0 & 56.9 & 24.1 & 78.1 & 63.5 & 39.0 & 75.9 & 60.9 & 39.9 \\
\hline
\end{tabular}


feet. We immediately notice the change in density altitude with dew-point temperature is not linear as was the case for the change in density altitude with temperature for the dry atmosphere. For example, moving in the horizontal along a constant temperature line, the density altitude changes by approximately 25 feet for a $5^{\circ} \mathrm{F}$ increase in dew-point temperature when starting with a dew-point temperature of $70^{\circ} \mathrm{F}$. In comparison, the density altitude only changes by approximately 10 feet when starting with a dew-point temperature of $35^{\circ} \mathrm{F}$. This can be traced back to Fig. 2 showing the non-linear change in virtual temperature, and therefore density, with increased dew-point temperature.

We also clearly see the change in density altitude with dew-point temperature (i.e., moving in the horizontal along a constant temperature line) is secondary when compared to the change in density altitude with temperature (i.e., moving in the vertical along a constant dew-point temperature line). For example, when moving in the vertical along a constant dew-point temperature line, the change in density altitude is approximately 290 feet per $5^{\circ} \mathrm{F}$ change in temperature. This is over ten times greater than the rate of change of density altitude with dewpoint temperature as seen in the previous paragraph.

We also notice the change in density altitude with temperature is nearly linear with temperature for a specified dew-point temperature (i.e., the spacing of the individual temperature lines are nearly equidistant regardless of the dew-point temperature). The linearity can again be traced back to the linearity of the change in density altitude with temperature for the dry atmosphere case. This is because according to (5), for a fixed dew-point temperature and pressure (or pressure altitude), the virtual temperature is simply a linear multiple of temperature. Thus because density altitude is linear with temperature for the dry case, it will also be a linear function of temperature for the moist case but with a slightly different slope. To see this, we take the derivative of (6) with respect to temperature while using (5) and holding both pressure and vapor pressure constant. The result is simply a constant multiplied by the change in density altitude with temperature for the dry

$$
\left(\frac{\partial h_{m}}{\partial T}\right)_{p, e}=\left(\frac{\partial h_{d}}{\partial T}\right)_{p} \gamma^{\left(\frac{-R_{d} L}{g_{o+R} L}\right)}
$$


case, i.e. where $\gamma \equiv[1-(e / p)(1-\varepsilon)]$ is a constant since both vapor pressure are pressure are held constant. Since $\gamma$ is a constant and near unity, the change in density altitude with virtual temperature will also be linear, but the rate of change will be a few percent less than for the dry case (e.g., approximately $1 \%$ less for standard mean sea-level pressure and a dew-point temperature of $60^{\circ} \mathrm{F}$ ).

For comparison, we have also produced the same chart for a pressure altitude of 6,000 feet in Fig. 3b. Figures $3 \mathrm{a}$ and $3 \mathrm{~b}$ are noticeably similar in shape, but the change in density altitude with dew-point temperature is slightly greater for the higher altitude case. For example, Fig. 3a shows an increase of approximately 290 feet over the $40^{\circ} \mathrm{F}$ range of dew point temperatures, while Fig. 3a shows an increase of approximately 340 feet over the same dew-point temperature range. This difference can again be traced directly back to Fig. 2 which shows the change in virtual temperature with the dewpoint temperature at different pressure altitudes. At higher pressure altitudes, the change in virtual temperature is greater for the same change in dewpoint temperature. However, since this effect results in a difference in density altitude of only approximately 50 feet over the entire $40^{\circ} \mathrm{F}$ range of dew- point temperatures, we, therefore, conclude pressure altitude does not significantly affect the degree to which humidity impacts density altitude calculations. Lastly, it is also of interest to note the change in density altitude with temperature for a specified dew-point temperature (i.e. moving in the vertical along a line of constant dew-point temperature) is similar in both cases at approximately 295 feet per $5^{\circ} \mathrm{F}$.

To better see the impact of dew-point temperature on density altitude for aviation purposes, we have created a nomogram of the absolute error (8) between the dry air case and the moist air case in Fig. 4. This figure clearly shows the range of potential errors with a maximum absolute error of approximately 400 feet for climatologically realistic values of dew-point temperature.

$$
\epsilon=h_{m}-h_{d}
$$


(a)

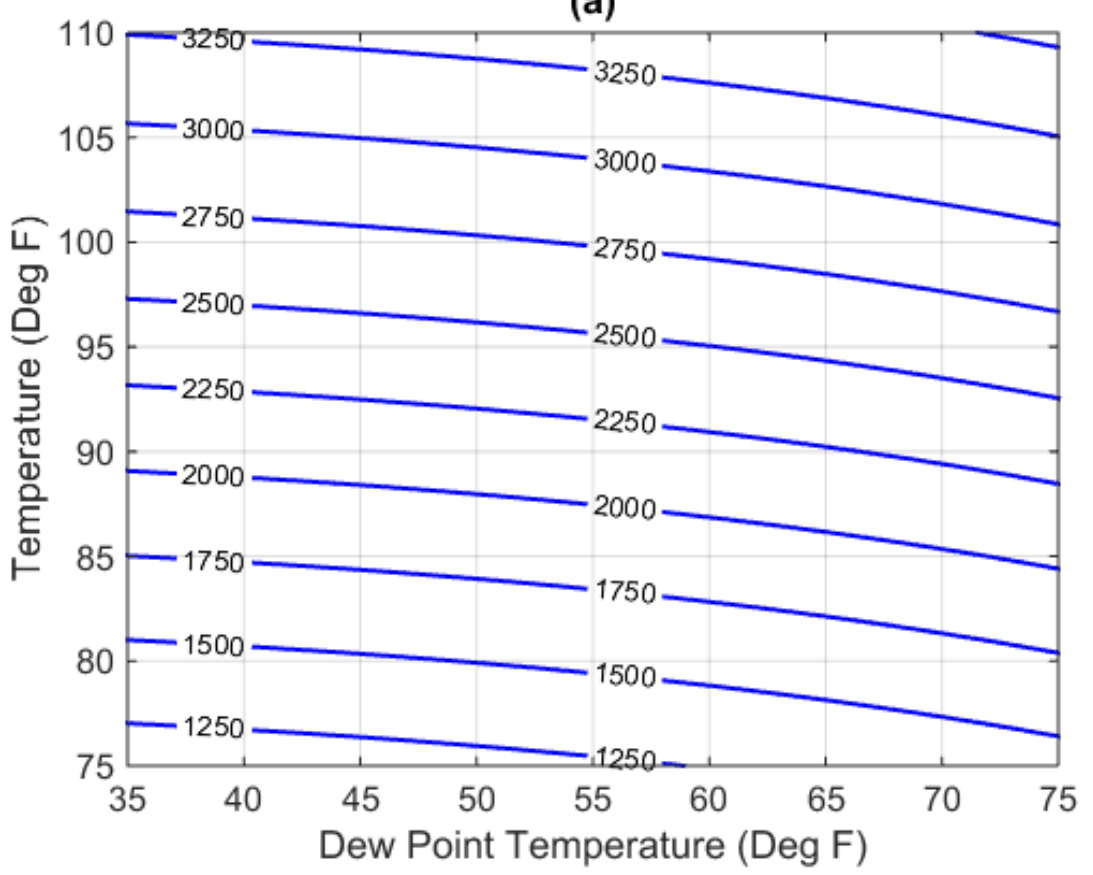

(b)

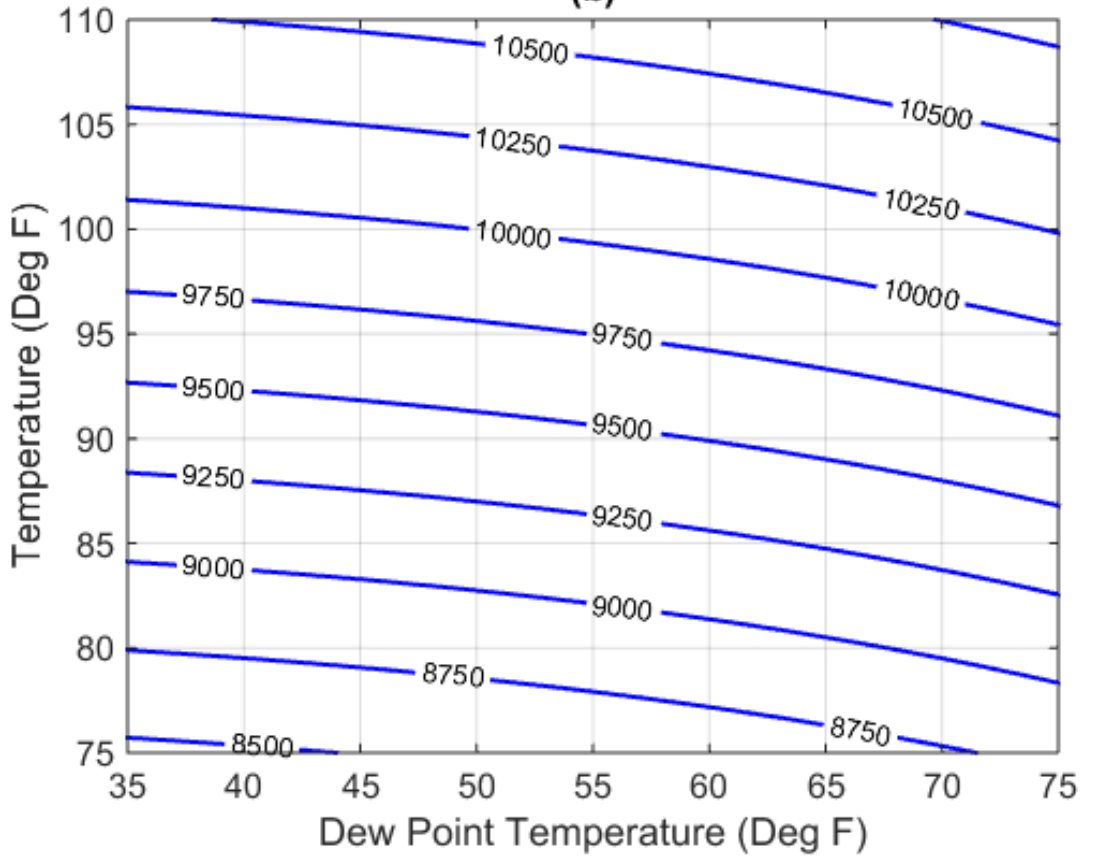

Figure 3. Density altitude (feet) as a function of temperature and dew-point temperature for (a) standard mean sea-level pressure and (b) a pressure altitude and a pressure altitude of 6,000 feet. 
(a)

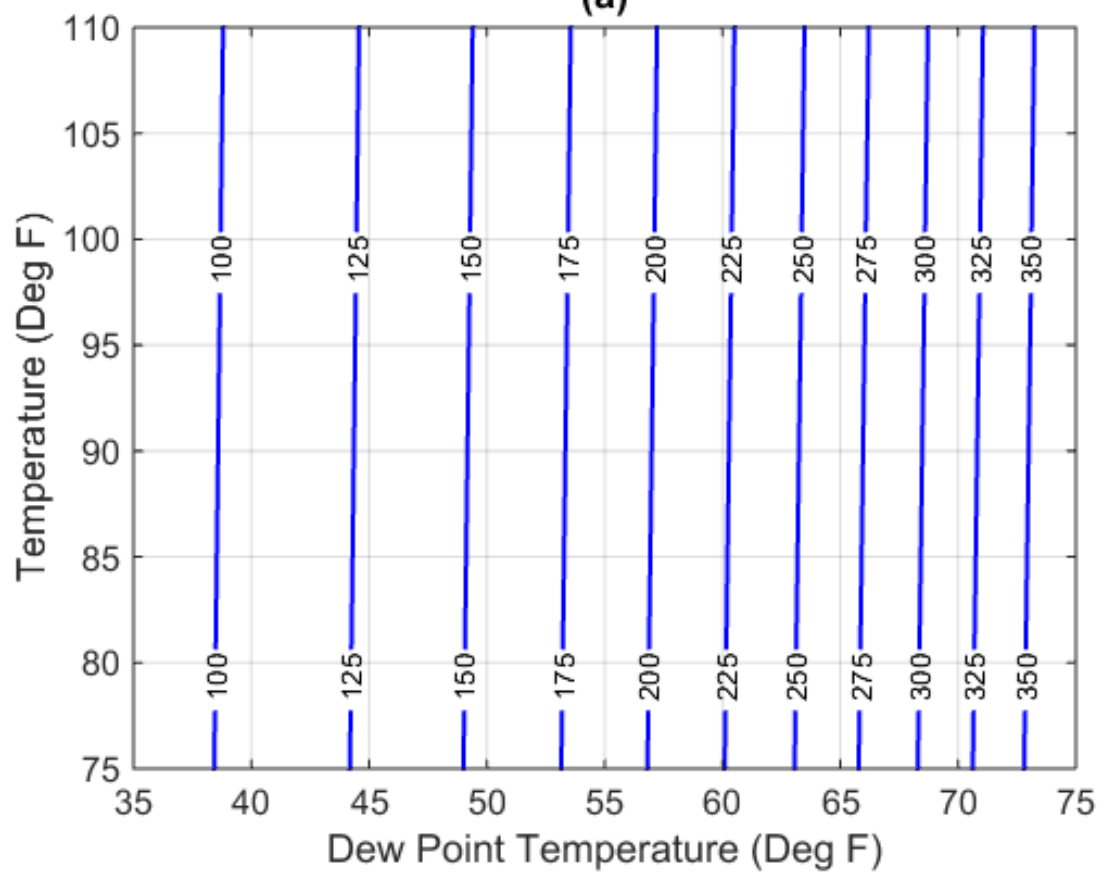

(b)

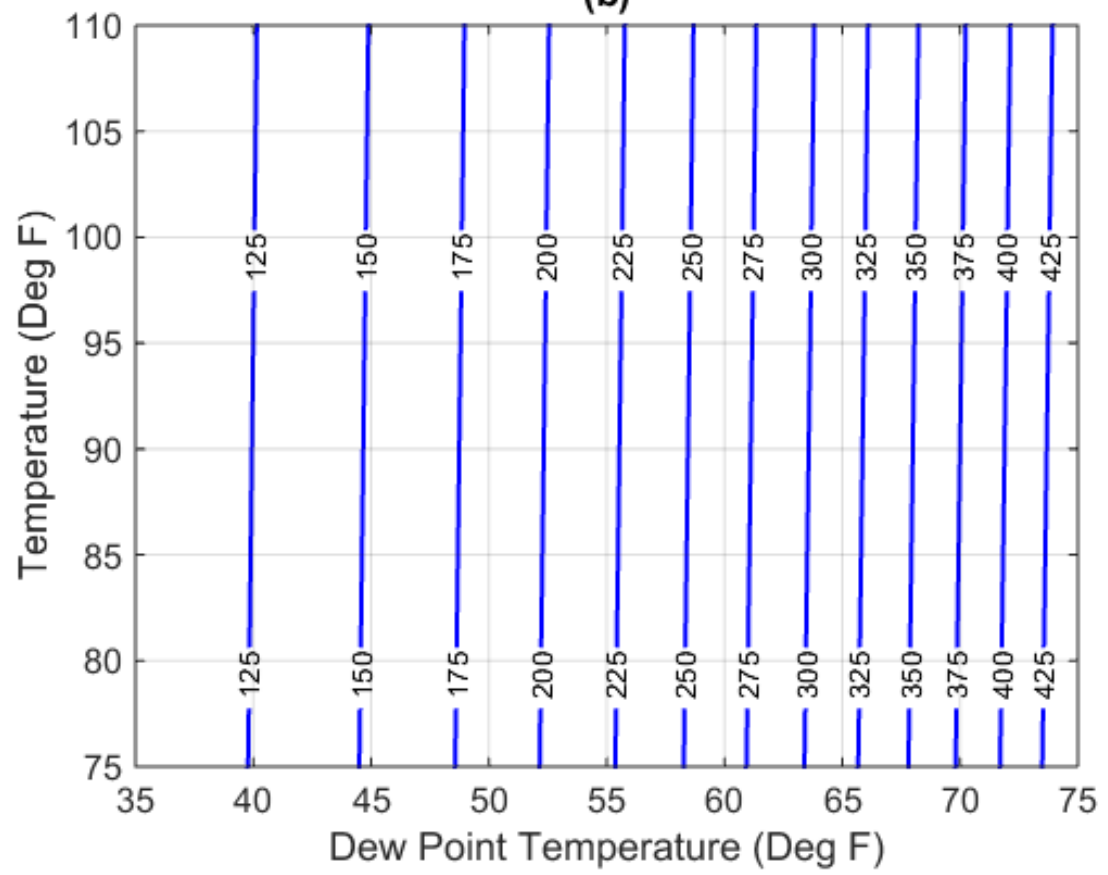

Figure 4. Absolute error (feet) in density altitude between the dry and moist case as a function of temperature and dew-point temperature for (a) standard mean sea-level pressure, and (b) a pressure altitude of 6,000 ft. 
Perhaps the most interesting aspect of Fig. 4 is that the error is nearly constant with temperature for a given dewpoint temperature. This can be traced back to the uniform vertical spacing of the plot lines in Figs. 3a and 3b. More importantly, this is a pedagogically significant concept because it demonstrates that the effect of humidity on density altitude for a given pressure altitude ultimately depends on the dew-point temperature, not the actual temperature or how close the air is to saturation (i.e., it shows density altitude's dew-point temperature dependence).

To demonstrate this point further, we have also constructed a graph displaying absolute error (8) over a range of relative humidity values for mean sealevel pressure (Fig. 5). Examining Fig. 5, we see that as we follow a relative humidity curve with increasing temperature, the absolute error increases. This behavior can be explained as follows. Since relative humidity is defined as the ratio of the actual vapor pressure to the saturation vapor pressure (the latter of which is a function only of temperature), then increasing the temperature while keeping relative humidity constant (i.e., following a relative humidity line) requires an increase in the moisture content (i.e., the actual vapor pressure or dew-point temperature). This is again an important pedagogical point. It is the increase in the air's moisture content (i.e., dew-point temperature) that is causing the increase in density altitude, not how close the air is to saturation. To see this more clearly consider the density altitude of the air for $60 \%$ relative humidity at a temperature of $60^{\circ} \mathrm{F}$. This combination results in an absolute error of approximately 130 feet. Now examine the absolute error for $20 \%$ relative humidity air at $100^{\circ} \mathrm{F}$, which is approximately 160 feet. So, despite having a significantly lower relative humidity, the error is slightly higher for the $20 \%$ relative-humidity case than for the $60 \%$ relative-humidity case. The reason is that because of the significantly greater saturation vapor pressure for $100^{\circ} \mathrm{F}$ air, a greater actual vapor pressure (i.e., higher dew-point temperature) is required to achieve a $20 \%$ relative humidity than is required to achieve $60 \%$ relative humidity at a temperature of $60^{\circ} \mathrm{F}$. So the relative humidity alone provides no information regarding the magnitude to which density altitude will be affected.

By comparison, the temperature used together with the relative humidity is more useful. For any specified temperature, an increase in relative humidity 


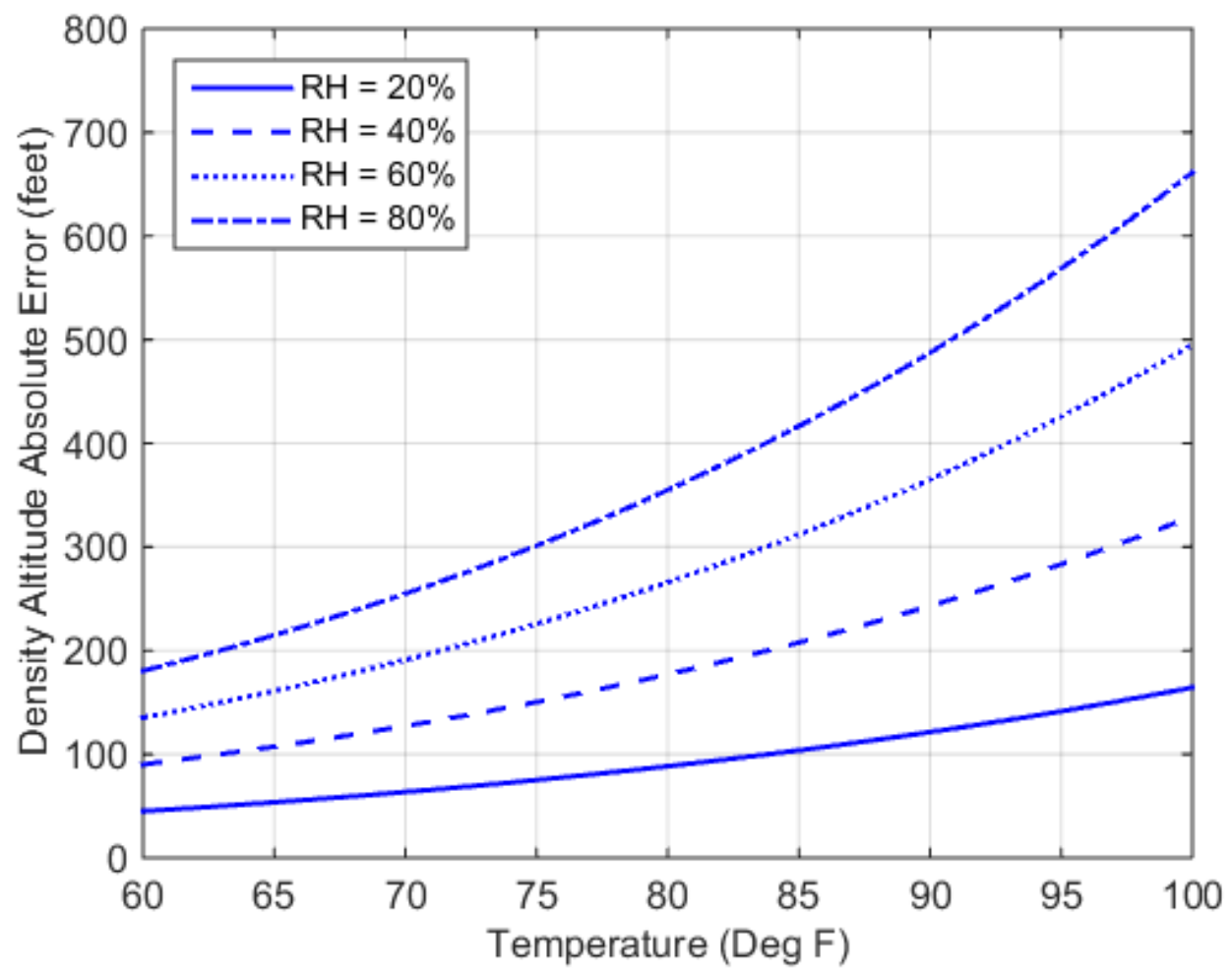

Figure 5. Absolute error in density altitude (feet) at mean sea-level pressure between the dry case and moist case as a function of temperature for four different relative humidity values. Positive error indicates how much higher the moist case density altitude would be compared to the dry case.

implies an increase in the water vapor content of the air, thereby leading to a greater absolute error. We can see this by moving vertically at a constant temperature line in Fig. 5. In doing so, we observe the error increases as the relative humidity increases. The relationship between moisture content and density-altitude absolute error also explains the comparatively larger spread in the curves at the warm temperatures compared to the spread at cooler temperatures. On the warm sides of Fig. 5, the saturation vapor pressures are much larger, and therefore a relative humidity of $80 \%$ requires a significantly greater actual vapor pressure (or dew-point temperature) than does the same relative humidity on the cold side of the chart. This can again can be related back to Fig. 2. In Fig. 2, the slope of the virtual temperature curves increases with increased moisture content (i.e. increased dewpoint temperature). In Fig. 5, we see this same effect. On the warm side of the figure the moisture content for a given relative humidity is greater than on the cool 
side; thus, the virtual temperature correction (and therefore density altitude error) is more significant leading to the large spread on that side. On the cold side of Fig. 5 , the actual vapor pressure for a given relative humidity value is comparatively less than that of the warm side, so the virtual temperature curve is much less sloped. The result is a much smaller spread in the density altitude errors on the cold side of the figure.

Returning to Figs. 4a and $4 \mathrm{~b}$ we notice that at mean sea level the absolute error ranges from approximately 95 feet for a relatively low dew-point temperature of $35^{\circ} \mathrm{F}$ upwards to approximately 375 feet for the relatively high climatological value (per Table 1) of $75^{\circ} \mathrm{F}$. In comparison, for the same range of dew-point temperatures at a pressure altitude of 6,000 feet, the absolute error extends upwards from approximately 100 feet to approximately 450 feet. While the absolute error lines are similar in shape for both standard mean sea-level pressure and a pressure altitude of 6,000 feet, the errors for the same temperature and dew-point temperature combinations are slightly greater for higher altitudes. Thus, altitude is a factor when determining the effect of humidity on density altitude calculations; however, it is a much smaller tertiary effect when compared to effects of temperature and dew-point temperature, themselves.

Also, despite the absolute error in density altitude being largest for warm temperatures and high pressure altitudes, it is relatively small compared to the density altitude, itself, under these same conditions. Therefore, another useful error measurement is the percent error, which we define as:

$$
\delta=\frac{\left(h_{m}-h_{d}\right)}{h_{m}} \cdot 100 \%
$$

The percent error $(\delta)$ adjusts the absolute error for large density-altitude values. Figures $6 \mathrm{a}$ and $6 \mathrm{~b}$ show the percent error in density altitude as a function of temperature and dew-point temperature at standard mean sea-level pressure and at a pressure altitude of 6,000 feet, respectively. We notice that for high dew-point temperatures, the percent error can be near $25 \%$ at mean sea-level pressure, while at a pressure altitude of 6,000 feet the same temperature and dew-point temperature combination results in an error of only $5 \%$. This is because while the absolute error 
(a)

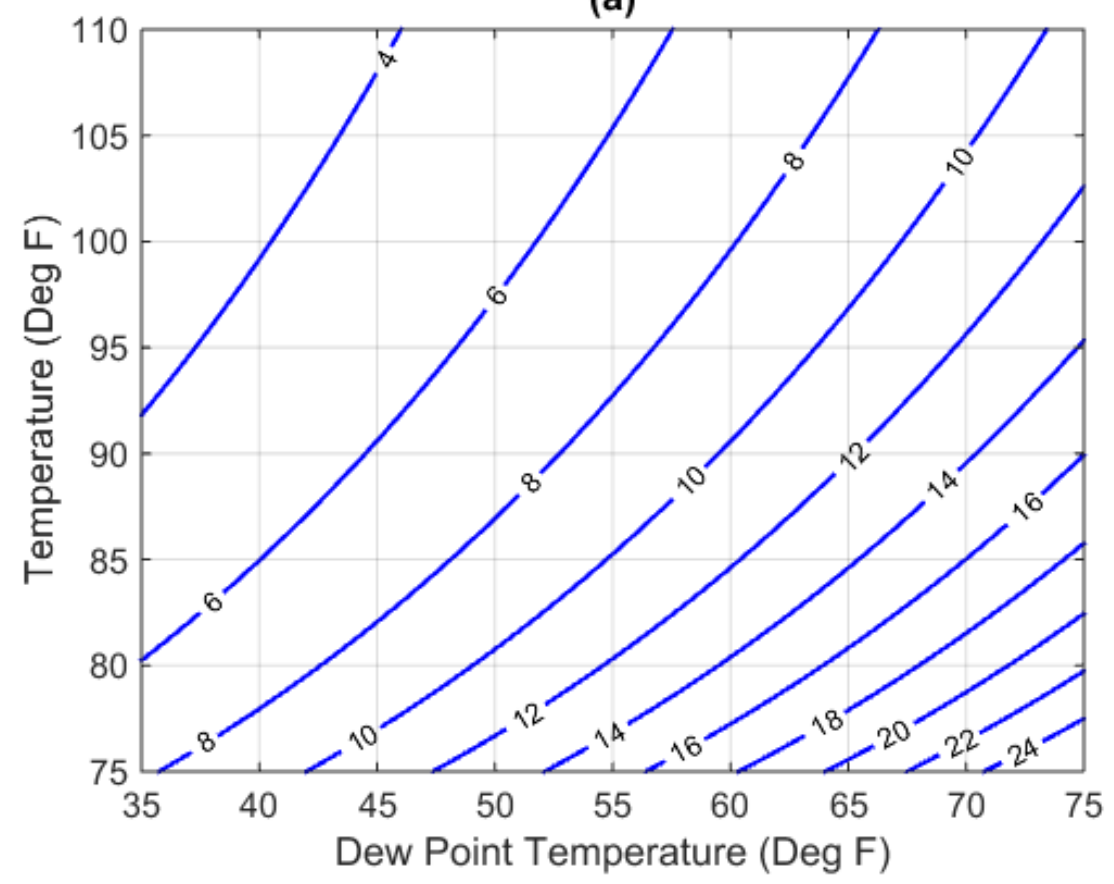

(b)

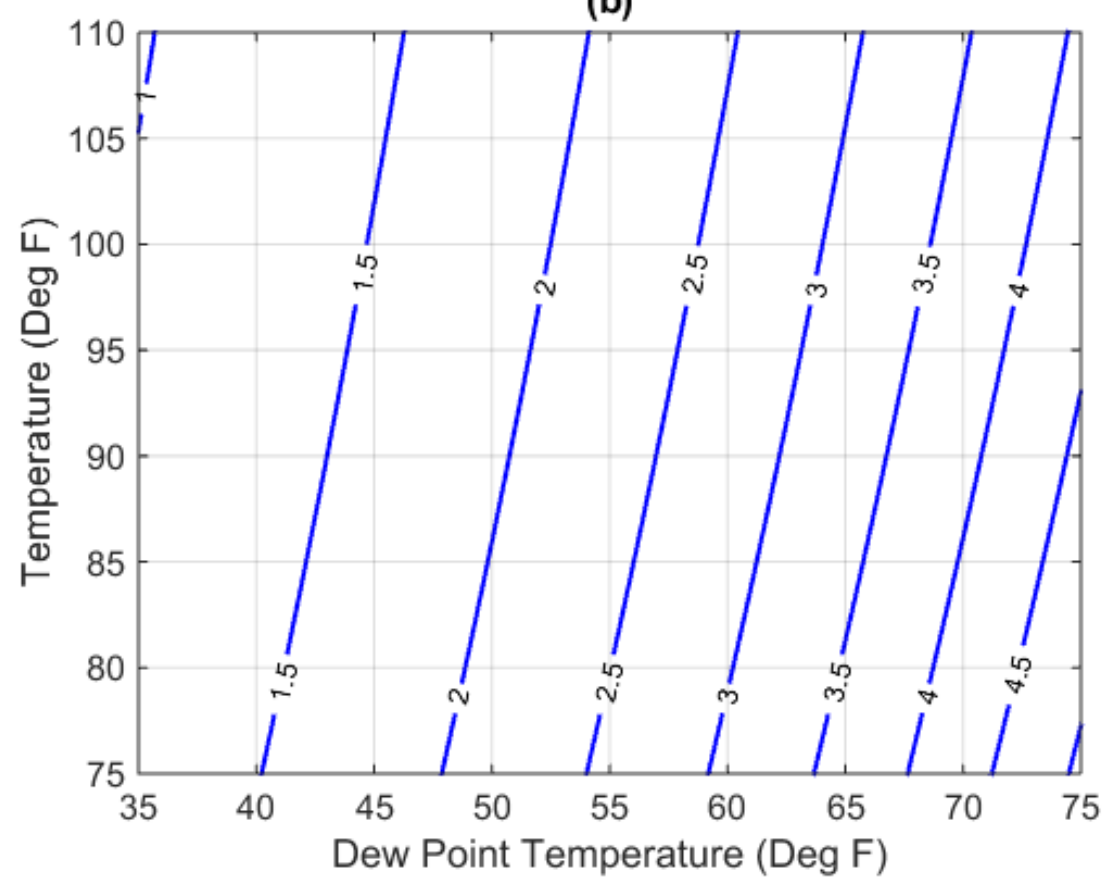

Figure 6. Percent error (\%) in density altitude calculations between the moist and dry case as a function of temperature and dew-point temperature for (a) standard mean sea level pressure, and (b) a pressure altitude of 6,000 feet. 
remains similar in both cases, the actual density altitude is far greater for a pressure altitude of 6,000 feet, resulting in a much lower percent error. An interesting pedagogical point is that while the absolute error for a given dewpoint temperature increases slightly with pressure altitude, the percent error decreases significantly. Thus, the significance of the humidity correction is far less at higher altitudes despite being slightly greater in magnitude.

\section{Development of a Simple Rule of Thumb (ROT)}

While the role of humidity in density altitude calculations is indeed secondary to the role of temperature, the effects can be potentially significant, when the dew-point temperatures are high (e.g., errors over 400 feet). Professional flight programs should endeavor to quantify the effects when possible so improved student decision making can be developed. Unfortunately, the non-linear nature of the effect of humidity on density altitude makes the development of a ROT more complicated than for the effect of temperature on density altitude. However, because the effect of humidity is secondary, the accuracy doesn't need to be as high to provide meaningful information.

For the ROT development, we conducted a linear regression analysis of density-altitude absolute error as a function of dew-point temperature for four pressure altitudes (0, 3,000 feet, 6,000 feet, and 9,000 feet) assuming a temperature of $30^{\circ} \mathrm{C}$. Note that we chose to use Celsius for the temperature scale instead of Fahrenheit for the ROT because METARs report Celsius. In addition, since the absolute error curves don't vary significantly with temperature as seen in Figs. 4a and $4 \mathrm{~b}$, the use of $30^{\circ} \mathrm{C}$ is purely arbitrary. The only requirement is the temperature values always remain greater than (or equal to) the dew-point temperature for the results to have physical meaning. Results from the linear regression appear in Table

2. The table shows the simple mean of the four linear regressions yielded a slope of 16.9 feet $/{ }^{\circ} \mathrm{C}$ with an average $y$-intercept of 27.7 feet and a nearly identical $\mathrm{R}^{2}$ values of 0.95 .

To construct a meaningful ROT, we sought an algorithm that was both relatively accurate as well as easy to use and remember. For this reason, we chose to use a slope of $20 \mathrm{feet} /{ }^{\circ} \mathrm{C}$, which is slightly higher than the average slope shown in Table 2, and a $y$-intercept of $0^{\circ} \mathrm{C}$, which is slightly less than that predicted by the 
regression. The utility of the $0^{\circ} \mathrm{C} y$-intercept is that it creates a very simple-to-use ROT; that is, we can find the correction in feet due to dew-point temperature by simply doubling the dew-point temperature and multiplying by ten or "doubling and adding a 0." An important caveat for the ROT is that it is only valid for dewpoint temperatures above freezing or else it would lead to negative corrections, which aren't physically sound, i.e. humidity should never lower the density altitude.

Figure 7 shows the bounding absolute error curves (standard mean sea-level pressure and a pressure altitude of 9,000 feet) as a function of dew-point temperature along with the ROT and the mean of the four linear regression parameters (slope and intercept). To evaluate the performance of the ROT and mean linear regression, we computed the root mean square error (RMSE) of both for all of the absolute error curves used in the computation of the means and provided the results in columns five and six of Table 2. The simple ROT does introduce slightly greater error compared to the mean linear regression, especially on the cold side of Fig. 7; however, this is where density altitude values would likely have less operational significance because the temperatures would most likely be lower than standard in this range as well.

Using this simple dew-point temperature ROT together with the traditional temperature ROT for density altitude makes for a simple correction that uses temperature, pressure altitude, and dew-point temperature. We first find density altitude using the 120 feet ROT (or a simple manual flight calculator), then add the adjustment due to the dew-point temperature. Thus the approximate moist density altitude $\left(\tilde{h}_{m}\right)$ can be defined as:

$$
\tilde{h}_{m} \equiv h_{d}+20 \cdot T_{d}
$$

While this ROT is no replacement for an electronic flight calculator, it does provide a simple means for approximating to the extent to which humidity effects density altitude. 
Table 2.

Linear Regression and ROT Results for Various Pressure Altitudes

\begin{tabular}{lccccc}
\hline $\begin{array}{c}\text { Prs. Alt. } \\
\text { (feet) }\end{array}$ & $\begin{array}{c}\text { Slope } \\
\left.\text { (feet } /{ }^{\circ} \mathrm{C}\right)\end{array}$ & $\begin{array}{c}\text { y-intrcpt } \\
\text { (feet) }\end{array}$ & $\begin{array}{c}\mathrm{R}^{2} \\
\text { (unitless) }\end{array}$ & $\begin{array}{c}\text { RMSE(RoT) } \\
\text { (feet) }\end{array}$ & $\begin{array}{c}\text { RMSE(Mean) } \\
\text { (feet) }\end{array}$ \\
\hline 0 & 14.8 & 24.3 & 0.95 & 53.7 & 35.0 \\
3,000 & 16.1 & 26.4 & 0.95 & 32.1 & 13.4 \\
6,000 & 17.6 & 28.7 & 0.95 & 7.9 & 10.8 \\
9,000 & 19.2 & 31.2 & 0.95 & 19.0 & 37.7 \\
\hline Mean & 16.9 & 27.7 & 0.95 & 28.2 & 24.2
\end{tabular}

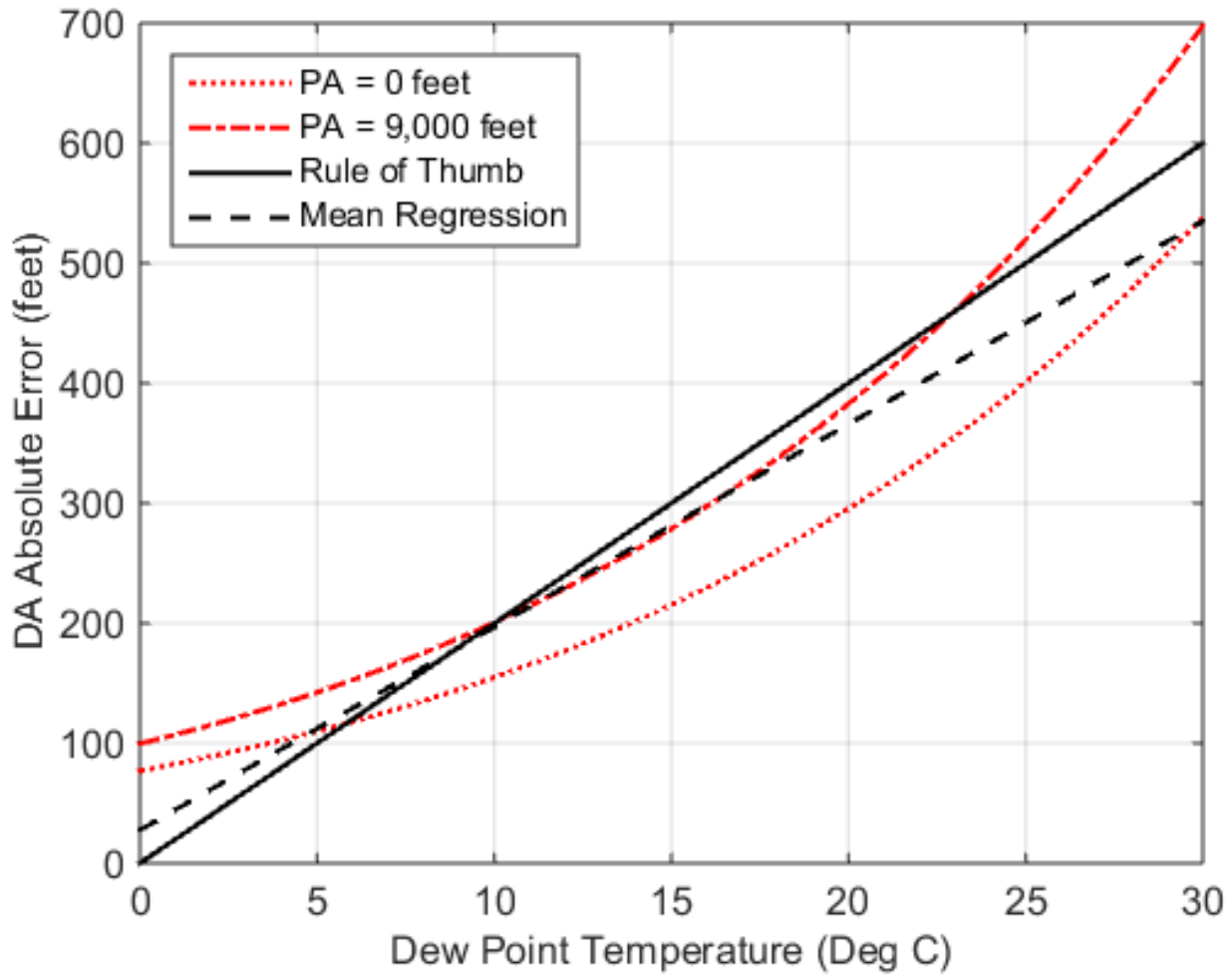

Figure 7. Absolute error in density altitude (DA) as a function of dew-point temperatures for a pressure altitude (PA) of 0 feet and a PA of 9,000 feet, both at a temperature of $30^{\circ} \mathrm{C}\left(86^{\circ} \mathrm{F}\right)$. Also plotted is a simple ROT approximation for the impact of dew-point temperature on density altitude and the mean regression line calculated from PAs of 0, 3,000, 6,000, and 9,000 feet. 
To examine the accuracy of the ROT more clearly, we have plotted the absolute error between the moist density altitude and dry density altitude (Fig. 8a) as well as the absolute error between the moist density altitude and the approximate moist density altitude found using the ROT (Fig. 8b). We define this absolute error for the ROT as:

$$
\epsilon_{R O T} \equiv h_{m}-\tilde{h}_{m}
$$

While the absolute error (Fig. 8a) increases significantly with dew-point temperature, the absolute error from the ROT is much smaller over the entire range of dew-point temperatures (Fig. 8b). Thus the ROT thumb does provide significant improvement compared to disregarding humidity entirely. We also see from (11) that when $\epsilon_{R O T}=0$, the ROT exactly predicts the true density altitude for the moist case. These zero values occur for all pressure altitudes in the $5-8^{\circ} \mathrm{C}$ dew-point temperature range of Fig. $8 \mathrm{~b}$. Beyond $8^{\circ} \mathrm{C}$ the $\epsilon_{R O T}$ is predominately negative, indicating the ROT is overcorrecting for the effects of moisture. The more hazardous case is that of under-prediction (positive $\epsilon_{R O T}$ ), which only occurs for the higher elevations at climatologically unlikely dew-point temperatures (as seen from Table 1), i.e. above approximately $25^{\circ} \mathrm{C}\left(77^{\circ} \mathrm{F}\right)$. Because dew-point temperatures this high could be possible, albeit rare, the ROT is best used for elevations of 6,000 feet or below when the humidity is extremely high. We should also note the use of a $0^{\circ} \mathrm{C} y$-intercept does result in large errors for dew-point temperatures near freezing; however, these quickly diminish as the dew-point temperature increases to $5^{\circ} \mathrm{C}$. In addition, the temperatures associated with dewpoint temperatures this low would likely be in the range where the role of density altitude is not a significant operational impact.

As another means of examining the ROT, we can define the percent error for the ROT as:

$$
\delta_{R O T} \equiv \frac{\left(h_{m}-\tilde{h}_{m}\right)}{h_{m}} \cdot 100 \% .
$$

Figures $9 \mathrm{a}$ and $9 \mathrm{~b}$ show the density-altitude percent error for the moist case vs. dry case using (9) and the density-altitude percent error for the moist case vs. the moist 
(a)

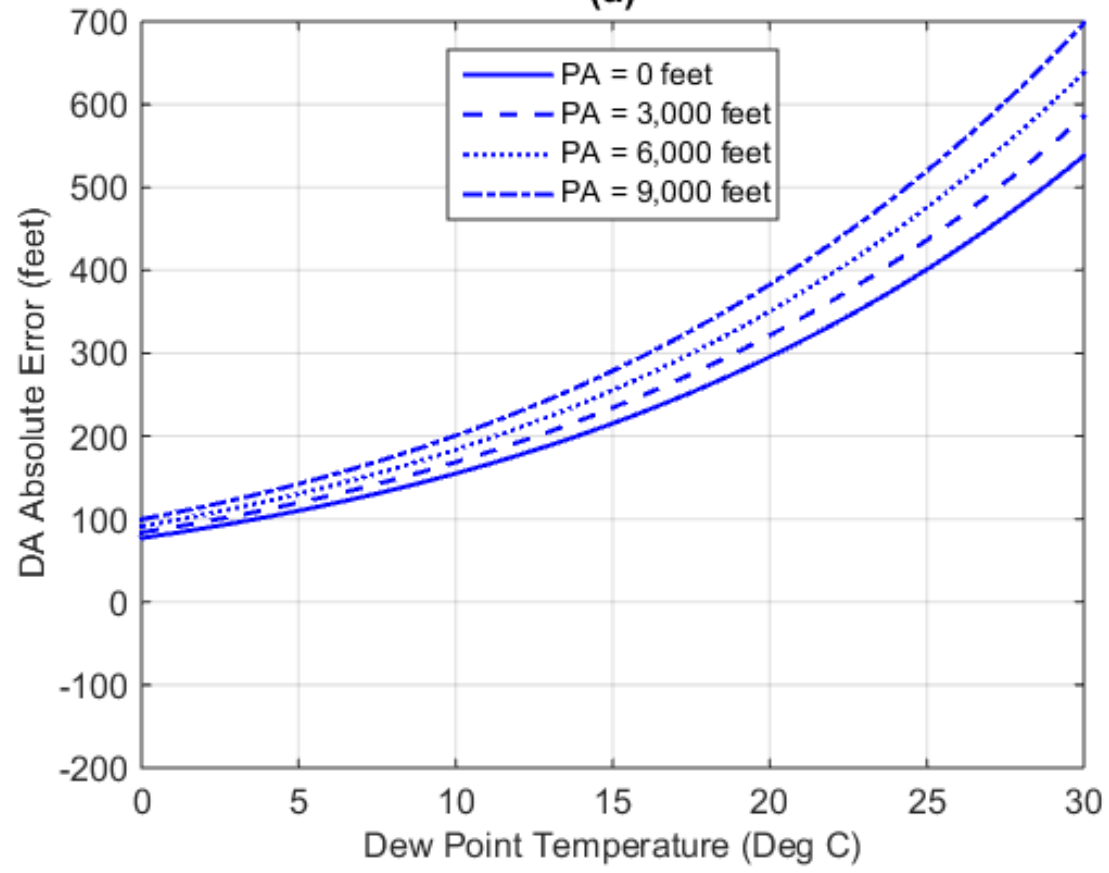

(b)

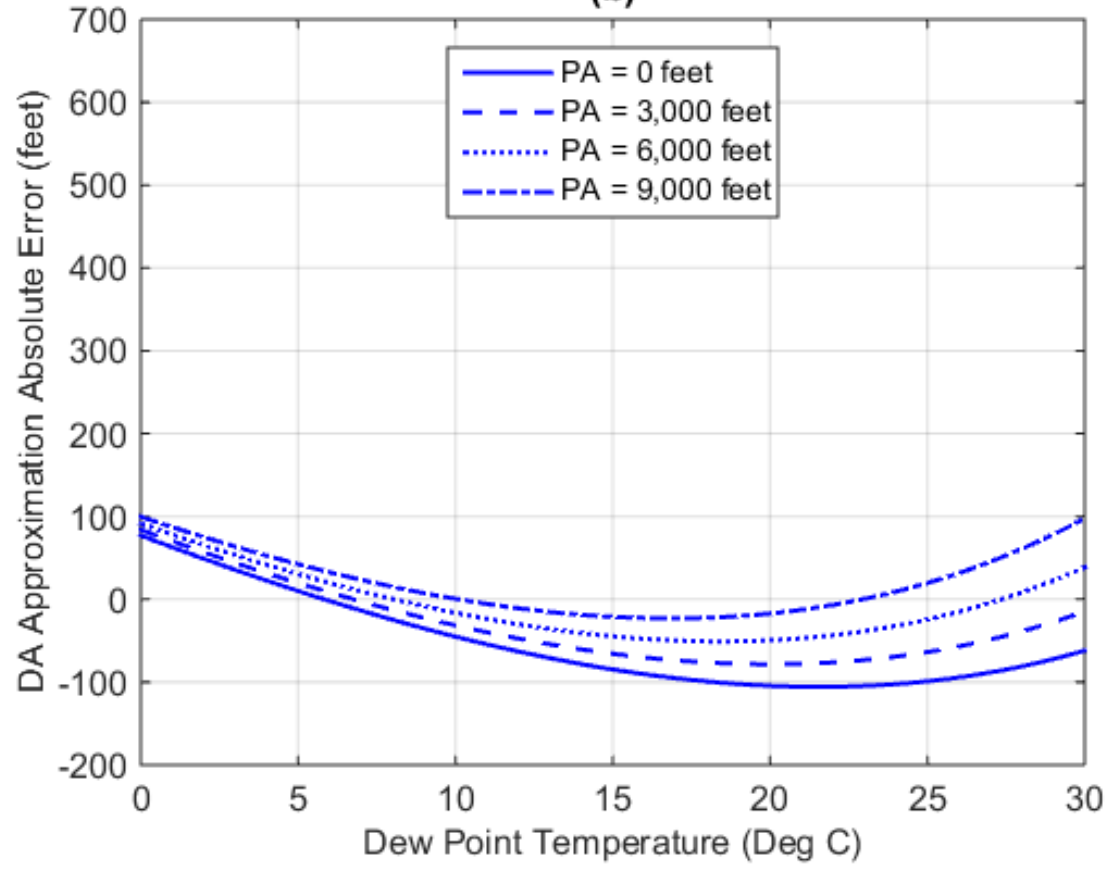

Figure 8. Density altitude (a) absolute error and (b) approximation absolute error as a function of dew-point temperature for four different pressure altitudes (PAs) at a temperature of $30^{\circ} \mathrm{C}$. 
approximation using (12), respectively. While the percent error for moist vs. dry increases monotonically with dew-point temperature, the percent error for the approximation first decreases then increases slightly but with a much lower magnitude. Except the standard mean sea-level pressure curve, we see from Fig. $9 \mathrm{~b}$ that the ROT predicts the density altitude within $\pm 2 \%$ for dew-point temperatures above $5^{\circ} \mathrm{C}$. Even at standard mean sea-level pressure, the ROT predicts the density altitude within $\pm 5 \%$. So while the ROT is not exact due to the nonlinear nature of the problem, it can be used to provide students with simple, "rough" measure of the secondary effect humidity has on density altitude calculations. This gives them a more objective means to quickly assess when the effect of humidity will be significant on their density altitude calculations, and when it will not.

\section{Discussion}

The purpose of this paper was to provide a comprehensive, quantitative and graphical description of the impacts of humidity on density altitude calculations as well as create a simple ROT to describe these impacts for use in professional aviation education. Here we highlight and discuss three important pedagogical points presented in the paper.

First, humidity is indeed secondary to temperature when examining the effects of each on density altitude. However, in high dew-point temperature environments, the effect can be operationally significant. It's important for professional pilots to have an understanding of the magnitude of the impact, so they understand when it is operationally significant. By providing graphical charts showing the impact of dew-point temperature on density altitude combined with a climatology of dew-point temperature values, students and instructors can easily demonstrate the conditions where humidity has an operational impact.

A second pedagogical point is that the effect of humidity is determined solely by the dew- point temperature and not relative humidity or even temperature dew-point spread. The effect of humidity is felt only through the vapor pressure, which is a function of dew-point temperature alone-not saturation. This is 
(a)

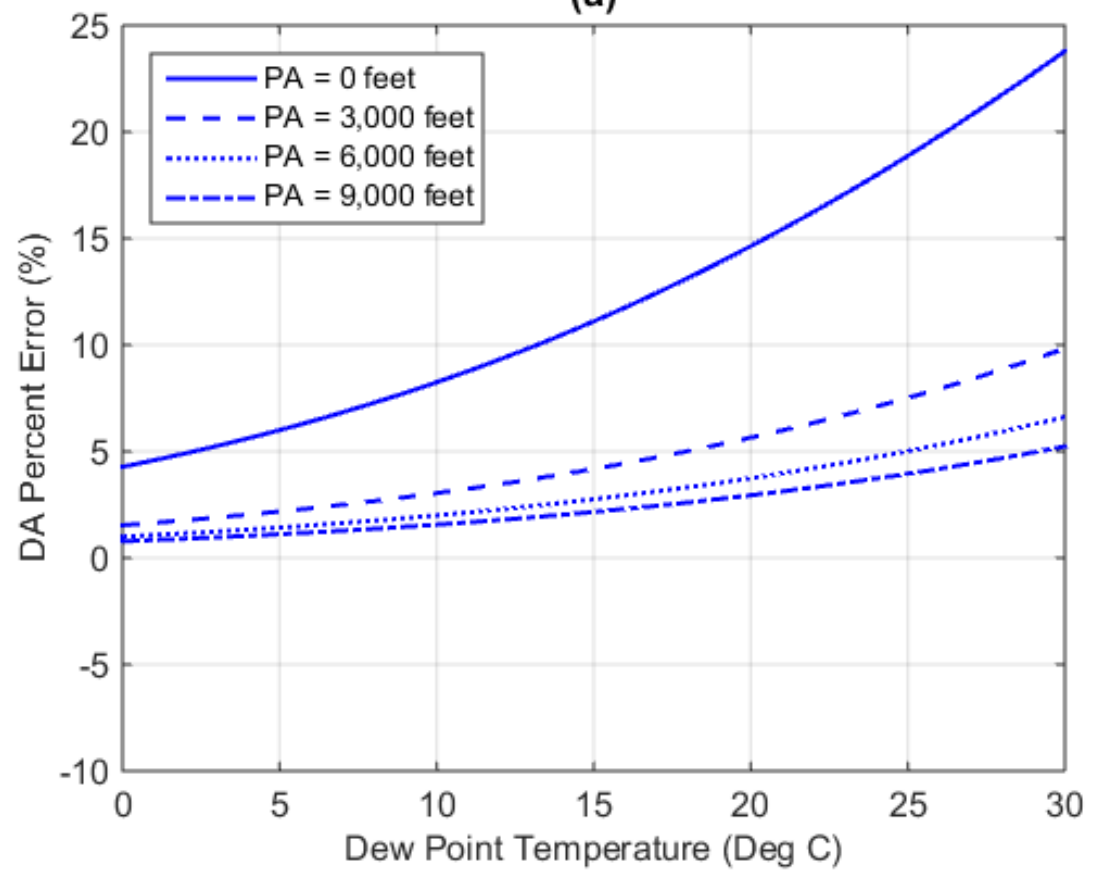

(b)

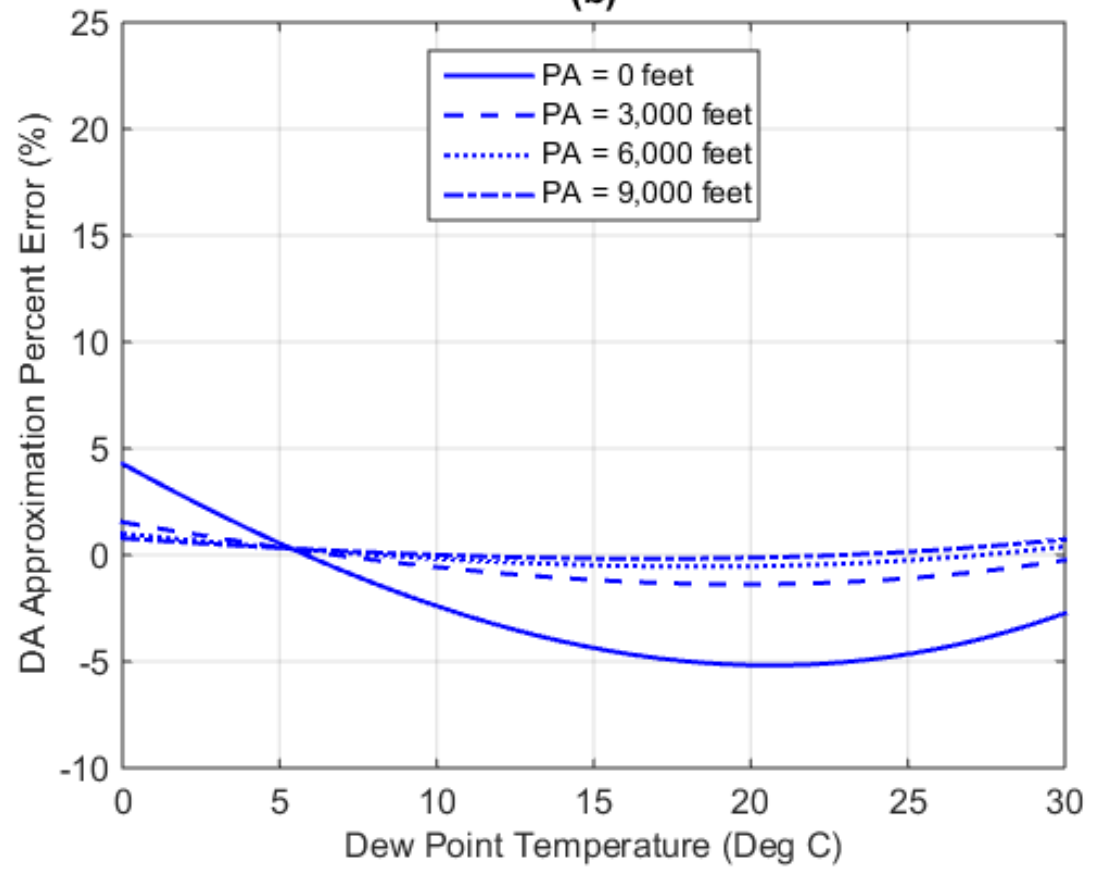

Figure 9. Density altitude (a) percent error and (b) approximation percent error as function of dew-point temperature for four different pressure altitudes (PAs) at a temperature of $30^{\circ} \mathrm{C}$. 
frequently a confusing concept for nascent students since relative humidity is often incorrectly associated with the air's actual moisture content in the media, despite only being a measure of how close the air is to saturation. Since warm air requires more water vapor to be saturated, the relative humidity only provides information on actual moisture content if the temperature is also known. Thus, low relative humidity air at high temperatures can have the same impact on density altitude calculations as high relative humidity air at low temperatures.

The third pedagogical point is that the elevation or pressure altitude at which the moist air is occurring has a smaller tertiary effect on the absolute error introduced into density altitude calculations than dew-point temperature itself. That is, the same dew-point temperature for air at 6,000 feet will have only a slightly greater impact on the density altitude than the same dew-point temperature air at mean sea level when all other factors are held equal. Despite the absolute errors being larger for higher altitudes, the relative error is significantly smaller. Thus the effect of humidity on density altitude calculations has a much greater relative impact near sea level.

\section{Limitations}

We present here several limitations regarding this study. First, we noted earlier that developing a simple, easy-to-use ROT is challenging because of the non-linear effects of humidity on density altitude calculations. Here we have attempted a linear regression method that sacrifices some accuracy to improve ease of use. The ROT is that the effect of humidity on density altitude in feet can be determined by multiplying the dew-point temperature (in ${ }^{\circ} \mathrm{C}$ ) by 20 . Colloquially, this can be stated as "doubling the dew-point temperature and adding a zero." While simple to use, there are some significant drawbacks. First, the dew-point temperature must be positive, and preferably greater than $5^{\circ} \mathrm{C}$. A negative value would imply moisture is decreasing the density altitude, which is not physically accurate. Second, the ROT is limited in that it can significantly overestimate the correction due to humidity by as much as $5 \%$ at mean sea level. We argue this is acceptable for educational purposes for two reasons: 1) the effect of humidity on density altitude is much smaller, secondary effect compared to temperature, and 2) the ROT overestimates rather than underestimates the correction for climatological values of dew-point temperature. The ROT therefore only provides a "rough" 
estimate that allows students to quickly determine the potential impact of humidity on density altitude. For operations, educators should stress the need to use flight calculators rather than the ROT for decisions where peak performance is required.

Having a feel for the magnitude of the impact dew-point temperature has on density altitude calculations is only useful if the user has an understanding of what typical dew-point temperatures exist for their locations. To that end, we created a ten-year climatology for locations that are both representative of a variety of climatic regimes throughout the U.S. as well as near various undergraduate professional flight programs. Our climatology is limited in that does not represent an entire period-of-record climatology for all months, but rather only provides a representative sample for the warmest calendar months when density altitude is the biggest concern and when dew-point values are likely to be greatest. Because the climatology only examines the most recent ten years of data, the maximum and minimum values are not necessarily record values. The table does, however, give students a sense of the magnitude of dew-point temperature values that can be expected at their locations. By combining the data in Table 1 with the graphical charts, students can gain a solid appreciation for the impact of humidity on density altitude calculations in their region of interest.

\section{Summary}

We have detailed the effects of humidity on density altitude calculations for various pressure altitudes and displayed the results graphically for use in professional aviation education. The charts capture the secondary nature of the effects of humidity on density altitude as well as the tertiary effects of altitude on humidity corrections. The study demonstrates how the effect of humidity at a given pressure is determined solely by the dew-point temperature and not how close the air is to saturation. Also, we created a simple ROT for describing the effects of humidity on density altitude calculations, which sacrifices some accuracy for ease of remembrance. Lastly, we provided a ten-year climatology of dew-point temperatures to provide a basis for the magnitude of the expected impact of humidity on density altitude at various locations. 


\section{Acknowledgement}

The authors would especially like to thank Mr. Daniel C. Oliva, P.E. for his careful examination of the equations and noted corrections. In addition, we would like to thank the anonymous reviewers for their insightful comments and suggested improvements. 


\section{References}

Glossary of Meteorology. $2^{\text {nd }}$ Ed. ([AMS], 2000), American Meteorological Society. $855 \mathrm{pp}$.

Bolton, D., (1980). The computation of equivalent potential temperature, Monthly Weather Review, 108, 1046-1053. doi: http://dx.doi.org/10.1175/15200493(1980)108<1046:TCOEPT>2.0.CO;2

Federal Aviation Administration ([FAA], 1975). AC 00-6A Aviation Weather for Pilots and Flight Operations Personnel. Washington, DC: Author.

Federal Aviation Administration ([FAA], 2008). FAA-H-8083-25A, Pilot's Handbook of Aeronautical Knowledge. Washington, DC: Author.

Federal Aviation Administration ([FAA], October 2014). AC 00-45G, Change 2. Aviation Weather Services. Washington, DC: Author.

Federal Aviation Administration Airman's Instruction Manual ([FAA], 2016). Official Guide to Basic Flight Information and ATC Procedures. Washington, DC: Author.

Flatau, P.J., Walko, R.L., \& Cotton, W.R. (1992). Polynomial Fits to Saturation Vapor Pressure. Journal of Applied Meteorology., 13, 1507-1513. doi: http://dx.doi.org/10.1175/1520-0450(1992)031<1507:PFTSVP> 2.0. CO;2

Guinn, T.A., \& Mosher, F.R. (2015). Numerical Model Derived Altimeter Correction Maps for Non-Standard Atmospheric Temperature and Pressure. International Journal of Aviation, Aeronautics, and Aerospace, 2(2). Retrieved from http://commons.erau.edu/ijaaa/vol2/iss2/4

Hyland, R.W. \& Wexler, A. (1983). Formulations for the thermodynamic properties of the saturated phases of $\mathrm{H}_{2} \mathrm{O}$ from 173.15 to $473.15 \mathrm{~K}$. ASHRAE Transportation, 89, 500-519.

Lester, P. (2007). Aviation Weather (3rd ed.). Englewood, CO: JeppesenSanderson. 
Lowe, P.R. (1974). An Approximating polynomial for the computation of saturation vapor pressure. Journal of Applied Meteorology, 16, 100-104. doi: http://dx.doi.org/10.1175/1520-0450(1977)016<0100:AAPFTC>2.0 $\mathrm{CO} ; 2$

National Oceanic and Atmospheric Administration ([NOAA], 1976). U.S. Standard Atmosphere, 1976. Document S/T 76-1562. Washington, DC: Author.

National Oceanic and Atmospheric Administration ([NOAA], 2015). Pressure Altitude. Retrieved from http://www.srh.noaa.gov/ images/epz/wxcalc/pressureAltitude.pdf.

National Centers for Environmental Information ([NCEI], 2016). Atmospheric data. Retrieved from http://www.ncdc.noaa.gov.

Wallace, J.M, \& P.F. Hobbs (2006), Atmospheric Science: An Introductory Survey. (2nd ed,), Amsterdam: Academic Press.

United States Air Force ([USAF], 1 March 1997). Weather for Aircrews. Air Force Handbook 11-203, Vol. 1. Washington, DC: Author. 


\section{Appendix A}

This appendix provides the derivation of the density altitude equation for dry air as well as the conversion from geopotential altitude to geometric altitude. To start, we first consider the atmosphere to be an ideal gas in hydrostatic balance. For a review of hydrostatic balance the reader is referred to Guinn and Mosher (2015). The hydrostatic balance equation can be written as

$$
\frac{d p}{d z}=-\frac{g p}{R_{d} T}
$$

where $p$ represents the atmospheric pressure, $z$ is height, $R_{d}\left(287.053 \mathrm{Jkg}^{-1} K^{-1}\right)$ is the gas constant specific to dry air, $g$ is gravity and $T$ is temperature.

Next, we assume a standard linear atmospheric temperature profile of

$$
T=T_{o}+L z
$$

where $T_{o}$ is the standard mean sea-level temperature of $288.15 \mathrm{~K}$ and $L$ is the standard tropospheric (0 to $11 \mathrm{~km}$ ) lapse rate of $-6.5 \mathrm{~K} / \mathrm{km}$ (NOAA, 1976). Substituting these values into (A1) while treating gravity as a constant with height, i.e., $g_{o}=9.80665 \mathrm{~ms}^{-2}$ (NOAA, 1976) yields the following expression.

$$
\frac{d p}{p}=-\frac{g_{o}}{R_{d}} \frac{d z}{\left(T_{o}+L z\right)}
$$

Integrating (A3) with respect to height from zero to an arbitrary geopotential altitude, $h(p)$, above standard mean sea-level pressure, $p_{o}$ gives:

$$
\frac{p}{p_{o}}=\left(1+\frac{L h}{T_{o}}\right)^{-\frac{g_{o}}{R_{d} L}} .
$$

Solving (A4) directly for geopotential altitude yields: 
$h_{d}(p)=\frac{T_{o}}{L}\left[\left(\frac{p}{p_{o}}\right)^{-\frac{R_{d} L}{g_{o}}}-1\right]$.

Equation (A5) provides an expression for the height of a given pressure in the standard atmosphere, i.e., the pressure altitude (PA). The subscript $d$ is used to indicate a dry atmosphere, i.e., no water vapor. This expression is similar in form to that used by the National Weather Service (NOAA, 2015). Our goal is to create an expression for the altitude at which a given density occurs in the standard atmosphere. To do this we simply use the ideal gas law to replace pressure with density, i.e.,

$$
p=\rho R_{d} T
$$

where $\rho$ is the air density. Since the ideal gas law applies to our standard temperature and pressure values as well, we also have:

$$
p_{o}=\rho_{o} R_{d} T_{o}
$$

Substituting (A2), (A6), and (A7) into (A5) and rearranging terms gives the desired relationship for the geopotential altitude of a given density in the standard atmosphere, i.e., density altitude. As before, the subscript $d$ indicates an assumed dry atmosphere.

$$
h_{d}(\rho)=\frac{T_{o}}{L}\left[\left(\frac{\rho}{\rho_{o}}\right)^{-\left(\frac{R_{d} L}{g_{o+R_{d} L}}\right)}-1\right]
$$

Because gravity was assumed constant for ease of calculations, the resulting heights from (A8) should be converted from geopotential altitude to geometric altitude for aviation use using the following conversion given in NOAA (1976) as

$$
Z=h \frac{R_{e}}{\left(R_{e}-h\right)}
$$

where $Z$ is the geometric height, $h$ is geopotential height, and $R_{e}=6,356,766 \mathrm{~m}$ (NOAA, 1976) is the mean radius of the Earth (assumed constant with latitude). 


\section{Appendix B}

Hyland and Wexler's (1983) formulation for saturation vapor pressure as a function of temperature is given as:

$$
e_{S}(T)=\exp \left[h_{4} \ln (T)+\sum_{i=-1}^{3} h_{i} T^{i}\right]
$$

where temperature is input in Kelvins and the non-dimensional coefficients are provided in Table B1. The saturation vapor returned by (B1) will be in units of Pascals. Equation (B6) is only valid for temperatures above freezing $(273.15 \mathrm{~K} \geq$ $T \geq 473.15 K$

Table B1.

Coefficients for Hyland and Wexler's (1983) Expression of Saturation Vapor Pressure over Water

\begin{tabular}{cl}
\hline Coefficient & Value (Dimensionless) \\
\hline$h_{-1}$ & $-0.58002206 \times 10^{4}$ \\
$h_{0}$ & $+0.13914993 \times 10^{1}$ \\
$h_{1}$ & $-0.48640239 \times 10^{-1}$ \\
$h_{2}$ & $+0.41764768 \times 10^{-4}$ \\
$h_{3}$ & $-0.14452093 \times 10^{-7}$ \\
$h_{4}$ & $+0.65459673 \times 10^{1}$
\end{tabular}

For temperatures below freezing, the equation is modified slightly to express the vapor pressure over ice. Here we have:

$$
e_{s}(T)=\exp \left[m_{6} \ln (T)+\sum_{i=0}^{5} m_{i} T^{i-1}\right]
$$

where the coefficients for the vapor pressure formulation are provided in Table B2. This expression is valid for the temperature range $(173.16 \mathrm{~K} \leq T<273.15 \mathrm{~K})$.

Table B2. 
Coefficients for Hyland and Wexler's (1983) Expression of Saturation Vapor Pressure over Ice

\begin{tabular}{cl}
\hline Coefficient & Value (Dimensionless) \\
\hline$m_{0}$ & $-0.56745359 \times 10^{4}$ \\
$m_{1}$ & $+0.63925247 \times 10^{1}$ \\
$m_{2}$ & $-0.96778430 \times 10^{-2}$ \\
$m_{3}$ & $+0.62215701 \times 10^{-6}$ \\
$m_{4}$ & $+0.20747825 \times 10^{-8}$ \\
$m_{5}$ & $-0.94840240 \times 10^{-12}$ \\
$m_{6}$ & $+0.41635019 \times 10^{1}$
\end{tabular}

Hyland and Wexler's equation provides the saturation vapor pressure; that is, the vapor pressure required for saturation at a given temperature. The actual vapor pressure is found by inputting the dew-point temperature rather than the temperature. 